\title{
Study on Three Levels and Objectives of Ecological River Construction
}

\author{
HE Wenxue ${ }^{1, \text { a }}$, Li Chaqing ${ }^{\text {2,b }}$ \\ ${ }^{1}$ Zhejiang Water Conservancy and Hydropower College, Hangzhou, China \\ 2 Zhejiang Water Conservancy and Hydropower College, Hangzhou, China \\ ahewx@zjwchc.com, blichq@zjwchc.com
}

Keywords: river construction; ecological river; building objective.

\begin{abstract}
The ecological river is one of the hot spots in river construction, but it is different that the river is in locations, size, function; the corresponding construction goal should also be different. Accordingly, the three levels and objectives of ecological river construction have been proposed in this paper, the progressive relationship is as follows: it is the first-level that the goals of flood control and drainage should be met, it is the second-level that the goals of water quality and flow conditions in the small discharge should be satisfied, it is the third-level that the goals of a virtuous circle between water-soil-organisms should be met in riparian zone. In the practices about the ecological river construction, according to the level of social and economic development and the needs the river building, the different building levels should be selectively met, so that the social benefits, ecological benefits and economic benefits can be better achieved.
\end{abstract}

\section{Introduction}

The rivers are like the vascellum of the earth, human chooses for living near the river, water is a basic element of development in urban and rural areas. The socio-economic rapid development and an accompanying series of water questions had made the function of the river in particular ecological function start to degrade, the ecological problems in the river must be focused on the water conservancy construction. From the past situation of engineering practices, the traditional river training works tend to focus on the slope stability, scouring and silting of the river bed and flood control, drainage, navigation, irrigation, water supply and other security needs and practical function, to achieve this purpose, many riverbanks and dams in water conservancy have been constructed. As everyone knows, because many structures have been built in the river, the river ecosystems have been influenced, the water pollution to be especially with the socio-economic rapid development has been made the ecological security worse.

Because the bank of river has excessively been protected by using the hard materials such as concrete, the natural connection between surface water and groundwater will be blocked, Not only lose their natural river morphology, and easy to make the river flow regime changes and consistent, so that the river water becomes more fragile ecosystems, water quality of the river's self-purification function tends to weaken. The lessons of experience in the realignment of a river over the past few decades had showed that the people have to be attached importance to the river ecosystems, and begin to practice the concept of ecological river construction. However, from the actual situation, the construction of ecological river may drown in misdirection. For example, the ecological river has been emphasized too much in the urban rivers, but the nature, functions, features of the river be often ignored, "abandon hardening", "deny canal" and "advocating green" has become a popular view. As everyone knows, the green riverside and beautiful scenery should be a superficies, and not is the innate character of river ecosystem, there is a difference and gap between "conceptual ecology" of "green = ecology" and a true ecological construction in the river, the "pseudo-ecology ${ }^{[2] "}$ to overlook the river features also exists objectively. For this reason, the water restoration, ecosystem rebuilding and landscape must be unified consideration and paid special emphasis in river construction, and through careful planning and scientific design, the comprehensive technology and measures of river ecological restoration and reconstruction should be used, so that the basic features of ecological river 
can gradually grow up, these features include that the river bank must be stable, biodiversity and safety of flood control must be effectively ensured, hydrology condition in riparian zone is good, a virtuous circle in water - soil - biology come into being, beautiful landscape begin to appear. Based on this concept and requirements, the river location, size, function and tasks must be considered in practical work, the selective construction levels and objectives should be studied and actualized, so that the socio-economic development needs in the river construction can be satisfied, the phase results of ecological river construction will be better reflected, the social, ecological and economic benefits in the ecological river construction will be incarnated too.

\section{Three levels and objectives about ecological river construction}

(1) The first-level goals: to meet the security needs of flood control and drainage

There are different scale and sizes in river, its location and degree of concern are different too, the tasks and specific functions in the local economic and social development will be diverse from each other, but the flood control and drainage in rivers always is the primary task, is the most main features, will belong to the first level of river regulation and ecological river construction, is the most basic the technical requirements, and must be achieved, it is a mandatory principle in the river construction to meet the appropriate standards for flood control and drainage.

The river, the flood control and drainage standards to meet the requirements of the river is essentially a sufficient flow capacity, that flood water can't bring harm to the surrounding farmland or urban villages.

It puts forward some requirements for the longitudinal and cross section design of the river, flood discharge and flood control level are the most basic design parameters of ecological river, and is a theoretical base to design a scientific and rational the river longitudinal and cross section, it is a technological requirement to protect the safety of flood control and drainage. Meanwhile, the correct and scientific flood scheduling scheme is a management requirements to ensure the safety of flood control and drainage, Harmony is the fundamental measure to ensure both the safety of flood control and drainage area.

This pair of longitudinal river, cross-sectional design made certain requirements, flood flow and flood control water level ecological river construction basic design parameters, is scientific and rational design of river longitudinal, cross-sectional theoretical basis, but also protect the safety of flood control and drainage technical requirements. The scientifically correct flooding scheduling scheme is to ensure the safety of flood control and drainage management requirements, coordination and unity of the two is a fundamental safety measures to ensure the regional flood control and drainage.

The longitudinal section of the river mainly consists of the bottom slope line, the water surface line, the dike (or canal) top line, and is the embodiment of the river shape on the space. The bottom slope line is limited by the topography and geological conditions of the river, there are a uneven bottom at the natural river, but the bottom slope line generally decline along the flow, this is the result of the natural evolution of the river bed. The bottom slope about artificial channel is usually a straight line, the slope depends on the landform conditions. Because the terrain slope is very small, the drainage channel at a coastal plain area often is at a flat slope. Water surface line is a direct reflection of the change rule of hydraulic factors (water level). The height depends on the discharge of the river, the bottom slope, the roughness coefficient, the cross-sectional shape and size, the shape of the river along the flow path and the number or structure of buildings, any change in one factor can lead to change in water depth or water level, it is an important factor in the flood control that must be determined by hydraulic calculation. Different boundary conditions and initial conditions should be designed so that the different hydraulic calculation in a steady flow and an unsteady flow can be analyzed. On the basis of the analysis and calculation in the different conditions, the appropriate safe height should be considered, in order to determine the dike elevation of corresponding channel can be confirmed. In addition, in order to guarantee the safety of embankments, sometimes the scour depth also need to be calculated.

(2) The second level goals: to meet the needs of good water quality and flow regime 
There is a changes of flood period and drought period in rivers as time goes on, the water quality and flow regime will be influenced by the change of water quantity, the change of river bed sediment will happen at the same time, aquatic organisms have lived and multiplied in the rivers, the ecological balance of the river will be maintaining. With the construction of a large number of water conservancy projects, the flood control safety have been guaranteed, but human greedy behavior to excessively seek the economic interests have been existed, and many negative effects to the ecological balance of the river have been happened. The excessive drain contamination is the direct cause of the watershed and regional water pollution, the governance about "three rivers and three lakes" is a national action to have surprised us, and the river ecological environment water demand[3] is a hot topic in field of water resource protection in recent years. Maintaining river eco-environmental water flow value generally is smaller, according to the requirements of the above flood control and drainage, the channel longitudinal, cross-sectional absolutely can ensure that the water does not overflow. But whether the water depth, flow rate, flow regime really meet the need of survival and reproduction of aquatic organisms will pay attention to another important issue in the ecological river construction. The velocity, water depth, flow regime, water quality in the condition of low flow will be an important indicator to keep the river habitat in the dry season, this belongs to the second level in the ecological river construction, also belongs to a higher level of the river construction.

(3) The third level goals: to meet the needs of virtuous cycle in between water- soil- organisms

It is the third level of ecological river construction to realize the virtuous circle in between watersoil- organisms, which belong to the highest level of ecological river construction, and it is also the most difficult to achieve the goals. Due to the complexity of the flow conditions and the difficulty of operation, the ecological river project of the general application is still under study. But such a solving scheme can considered: according to the groundwater distribution characteristics, the necessary engineering measures should be used in the appropriate distance and suitable topographical condition, combination scheme of artificial wetland and artificial lake maybe constructed, the smooth exchange places about surface water and groundwater should be provided in a local river, it is also a flood-storage project. Not only the drawbacks that the plane shape of the whole channel is single, the cross-sectional shape is uniform, revetment style is rigid will be avoided, but also a living environment of aquatic organisms to satisfy the benign cycle demand between water-soil-biology will be created, and the leisure and entertainment landscape can be provided for the local, the technical scheme should be constantly improved in practice. For example, if the river is through the city or residential areas, it is necessary to construct riparian green landscape, which is an important part of the urban landscape, it also is a part of the public recreational facilities, the construction standards and scale will be limited by the regional importance, construction funds, and the implementing width in the riparian zones, it should be determined on the basis of scientific research and comprehensive analysis.

\section{Conclusion}

The construction of ecological river must be propitious to rehabilitate or reconstruct an aquatic ecological environment and to promote harmony between human and water under the premise to guarantee the safety of flood control and drainage. In practical work, the flow area of the river, the topography of river sides and bottom slope, rangeability of water level and so on should be first considered, meanwhile, on the basis of the comprehensive analysis and research, according to the local government and the people's expectations, combined with the local fiscal capacity and the level of economic and social development, the river ecological construction scheme to have a different levels and objectives can only be determined, the different development goals will be progressively achieved. Secondly, the construction of ecological river must accommodate to the local conditions, namely the construction scheme must be suitable for the hydrological information of a river, it is wrong to only aim at ecological target and to ignore the durability and stability of revetment material in the practice, this situation must be resolutely avoided. Otherwise, the unexpected disasters maybe appear, such behavior of river regulation must be stop. Finally, it must be emphasized that the three 
levels and objectives about the ecological river construction have the interdependent and progressive relation, the first level goals about flood control security must be satisfied, the corresponding technical projects must keep coordination with the local economic and social development level, the location of the river and the main function characteristics, so that the best technical and economical effects in the construction of ecological river can be achieved.

\section{References}

[1] Zhao Yansong et al. Analysis of some problems in ecological river management. Science \& Technology Information, 2011,(23):p.709.(In Chinese)

[2] CHEN Yu-quan et al. Quantity calculation of water diversion for improving water quality of Chongming Island. Journal of Anhui Agricultural Sciences, 2012,40(28):13957-13959. (In Chinese)

[3] PAN Zharong et al. Research progress on river ecological flow requirements. Journal of Water Resources \& Water Engineering, 2011, 22(4):p.89 94. (In Chinese) 